DOI: 10.12731/2218-7405-2018-12-103-113

УДК 159. 9

\title{
ИССЛЕДОВАНИЕ ТРЕВОЖНОСТИ ВЕРУЮЩИХ И НЕВЕРУЮЩИХ МОЛОДЕЖНОЙ СРЕДЫ
}

\section{Кокоева Р.T.}

В современном российском обществе в настоящее время наблюдается поступательное движение в сторону изучения и анализа мировых религий. Это способствует тому, что, опираясь на демократические иченности циивилизации, наше правительство формирует такое пространство, в котором представители разных религиозных конфессий, этносов, чувствуют себя достаточно комфортно. Верующий человек, содержательно наполненный религиозным чувством, эмочиией, религиозными иенностями, открыт миру, экзистенциально активен во внешней сочиальной среде. Такая структура религиозности дает возможность верующей личности развиваться, реализовать свой духовный потенциал и в целом, жизненный замысел. В работе проанализировано субъективное и объективное отношение молодежи к религиозной вере, уровни тревожности двух сочиальных групп респондентов: верующих и неверующих, соответственно - юношей и девушек.

Цель. Статья посвящена исследованию религиозности юношей и девушек, эмоциональной защищщенности, выявлению уровня ситуативной и личностной тревожности у верующих и неверующцих молодежной среды.

Методами исследования явились анкетирование, опрос.

Научная новизна - использована авторская анкеты для выявления эмоционального чувства по отношению к религии среди юношей и девушек.

Результаты проведенного исследования показали следующее: юноши более религиозны, чем девушки, эмоционально защищены, девушки в меньшей степени религиозны, эмоционально менее устойчи- 
вы, нежели юноши (прихожане), более тревожны, нежели юноши.

Область применения результатов. Исследования могут послужить информативно-содержательной основой в изучении психологии религиозного сознания представителей православной традиции в образовательной сфере, сочиальных учреждениях.

Ключевые слова: религия; православная традиция; религиозность; верующий; неверующий; взаимосвязь; тревожность.

\section{STUDY OF THE ANXIETY OF BELIEVERS AND NON-BELIEVERS AMONG YOUNG PEOPLE}

\section{Kokoeva R.T.}

In the modern Russian society there is at present currently a forward movement towards the study and analyses of world religions. This contributes to the fact that based on democratic values civilization, our govemment forms such a space in which representatives of different religions confessions, ethnic groups, feel quite comfortable. A believer, full of content religions feeling, emotion, religious values, open to the world, existentially active in the external social environment. Such structure of religion gives opportunity for religions person to develop, to realize your spiritual potential and, in general, your life plan. The article is devoted to the question of interrelation of religions personality with the level of anxieties. The paper analyzes the personal and situational, anxiely of two groups of respondents: believers and non-believers. Analysis of empirical data is found, what the unbelievers of personal and situational anxiety is higher than that of believers.

Purpose. The article is devoted to the study of the religiosity of young men and women, emotional security, identifying the level of situational and personal anxiety among believers and non-believers of the youth environment.

Methodology. The study was a questionnaire survey. Scientific novelty-the author's questionnaire is used to identify emotional feelings towards religion among boys and girls. 
Results. The results of the study showed the following: boys are more religious than girls, emotionally protected, girls are less religious, emotionally less stable than boys (parishioners), more anxious than boys. The scope of the results.

Practical implications. Research can serve as an informative and informative basis in the study of the psychology of religious consciousness of representatives of the Orthodox tradition in the educational sphere, social institutions.

Keywords: religion; Christian tradition; religion; believer; unbeliever; relationship; anxiety.

Религия как социальное явление в России претерпевала различную амплитуду интереса со стороны общества. Возрождение православной традиции наблюдалось, как известно, в период распада Советского союза - снятие идеологических запретов привели православную религию к новому осознанию христианского мироощущения и мироустройства. Восприятие окружающего мира, реализация своего жизненного замысла через православную доктрину привела к росту обращения личности в сторону религиозного сознания, особенно молодежи. Современный молодой человек четко понимает, что рыночная ориентация ввергает его в такие условия, в рамках которых он должна быть максимально адаптивным, менее тревожным. И если для определенной категории людей, характеризующейся индивидуальными личностными особенностями в определенной социально-психологической ситуации свойственно обращение к техникам ауторегуляции, как психологической помощи, способствующие снижению, в частности, тревожности, то для другой группы, оптимальное решение - обращение к религиозной вере, как способу освобождения от негативных психоэмоциональных состояний. Обращение к православной традиции в трудных жизненных ситуациях на сегодняшний день в нашей стране поступательно набирает силу, в виду все большего интереса, как к самой православной вере, так и ее практической психологической помощи. 
Синдром тревожного мира - общая характеристика современного личностного и социального пространства человека. Молодежь в поликультурном и многоконфессиональном обществе как детерминанта всех социальных потребностей, интересов и ожиданий социума точно реагирует на события и явления, формируемые этими данностями. Психология религии опирается на доминирующее значение социальных факторов, влияющих на формирование религиозной веры, но на нее влияет и психологические особенности личности юношей и девушек, их гендерных характеристик и возрастные особенности развития. Религиозная вера как психологический феномен представляет собой ценность для религиозной личности и ценность для общества в способе организации, сбалансированности и стабилизации психоэмоционального состояния личности, в духовном развитии и саморазвитии человека в социуме. Наше исследование в своей теоретической структуре базируется на психоаналитической концепции К.Г. Юнга, который подчеркивает психологическое начало религии и анализирует ее с научной точки зрения. Ученый рассматривает религию как потребность человека в его стремлении к психическому здоровью. Обращение человека к религии - это необходимость, стремление его к душевному успокоению, психическому равновесию. Не менее глубоко о признании религии в социоэкономической жизнедеятельности современного человека высказался основоположник неофрейдизма Э. Фромм. Он указывал на то какова религия [6, с. 156], или же религия, способствующая развитию личности, реализации своего экзистенциального замысла, или же религия, наоборот, препятствует развитию личности. Показательно такое глубинное понимание религии и ее влияния на жизнеспособность личности определил блестящий ученый-практик, автор логотерапии Виктор Франкл, который считал, что если религия способствует реализации жизненного замысла человека, то она, безусловно, становится частью жизни личности, способом психологической помощи. Такая трактовка религиозности расширяет ее психические возможности и положительного влияния на жизнеспособность личности. Особого внимания заслуживает 
молодежь, как активная развитая социальная группа нашего общества. В свою очередь известный американский психолог Г. Оллпорт, рассмотрев психологическую типологию религиозных личностей, вычленил одну из особенностей религии - ее ценностность, связанной с органической функциональностью, а, значит, практической духовной полезностью. Кроме того, в работе мы опирались на концептуальные положения отечественных ученых - Братусь Б.С., Леонтьев Д.А. и Петровский А.В., а также исследователей в области религиозного сознания Василюка Ф.Е.. Грановской Р.М., Демьянова А.И., Иваненко С.И.

Мы исследовали молодых людей в количестве 25 человек в возрасте 16-17 лет - экспериментальную группу составили 11 человек (мальчики верующие, прихожане Православной церкви Пресвятой Богородицы) и контрольная группа, в состав которой вошли 14 человек - неверующие, девочки в возрасте 16-17 лет горожане г. Владикавказ. Респонденты была предложена следующая процедура: сначала была проведена авторская анкета, в котором выявилось субъективное и объективное отношение молодых людей к религиозной вере, эмоциональному состоянию, дополненная методикой Ч. Спилбергера.

Авторская анкета, состоящая из 12 приведенных ниже вопросов.

\section{1. Важна ли религиозная вера для молодого человека?}

Таблица №1.

\begin{tabular}{|c|c|c|c|c|c|c|}
\hline Ответы & Девушки - 14 & $\%$ & Юноши - 11 & $\%$ & Количество & Общий \% \\
\hline да & 5 & 36 & 9 & 82 & 14 & 56 \\
нет & 9 & 64 & 1 & 9 & 10 & 25 \\
не знаю & - & - & 4 & 36 & 4 & 16 \\
\hline
\end{tabular}

\section{2. Как часто Вы обращаетесь в вере?}

Таблица №2.

\begin{tabular}{|c|c|c|c|c|c|c|}
\hline Ответы & Девушки - 14 & $\%$ & Юноши - 11 & $\%$ & Количество & Общий \% \\
\hline часто & - & & 9 & 82 & 9 & 36 \\
иногда & 3 & 21 & 4 & 36 & 7 & 28 \\
редко & 11 & 79 & - & - & 11 & 44 \\
\hline
\end{tabular}




\section{3. В каких обстоятельствах Вы обращаетесь к вере?}

Таблиияа №3.

\begin{tabular}{|l|c|c|c|c|c|c|}
\hline \multicolumn{1}{|c|}{ Ответы } & Девушки - 14 & $\%$ & Юноши - 11 & $\%$ & Количество & Общий \% \\
\hline В сложных & & & & & & \\
ситуациях & 5 & 36 & 7 & 64 & 12 & 48 \\
Когда одинок (а) & - & & 3 & 27 & 3 & 12 \\
Когда не с кем & & & & & & 4 \\
посоветоваться & 9 & 64 & 1 & 9 & 9 & 36 \\
Не обращаюсь & - & - & - & - & - & - \\
\hline
\end{tabular}

\section{4. Считаете ли вы, что религия способствует развитию человека?}

Таблица №4.

\begin{tabular}{|l|c|c|c|c|c|c|}
\hline \multicolumn{1}{|c|}{ Ответы } & Девушки - 14 & $\%$ & Юноши - 11 & $\%$ & Количество & Общий \% \\
\hline Да & 4 & 29 & 8 & 73 & 12 & 48 \\
Нет & 3 & 21 & 1 & 9 & 4 & 16 \\
Затрудняюсь \\
ответить
\end{tabular}

\section{5. Вера в Господа, выполнение православных ритуалов} и заповедей придает Вам уверенности?

Таблииа №5.

\begin{tabular}{|l|c|c|c|c|c|c|}
\hline \multicolumn{1}{|c|}{ Ответы } & Девушки - 14 & $\%$ & Юноши - 11 & $\%$ & Количество & Общий\% \\
\hline Да & 3 & 21 & 9 & 82 & 12 & 48 \\
Нет & 6 & 43 & 1 & 9 & 7 & 28 \\
$\begin{array}{l}\text { Затрудняюсь } \\
\text { ответить }\end{array}$ & 5 & 36 & 1 & 9 & 6 & 24 \\
\hline
\end{tabular}

\section{6. Считаете ли Вы, что религия делает лучше человека?}

Таблииа №6.

\begin{tabular}{|l|c|c|c|c|c|c|}
\hline \multicolumn{1}{|c|}{ Ответы } & Девушки - 14 & $\%$ & Юноши - 11 & $\%$ & Количество & Общий\% \\
\hline да & 4 & 29 & 9 & 82 & 13 & 52 \\
$\begin{array}{l}\text { нет } \\
\text { затрудняюсь } \\
\text { ответить }\end{array}$ & 1 & 7 & - & - & 1 & 4 \\
\hline
\end{tabular}

\section{7. Может ли религия положительно повлиять на человека?}

Таблициа №7.

\begin{tabular}{|l|c|c|c|c|c|c|}
\hline \multicolumn{1}{|c|}{ Ответы } & Девушки - 14 & $\%$ & Юноши - 11 & $\%$ & Количество & Общий\% \\
\hline да & 2 & 14 & 8 & 73 & 10 & 25 \\
$\begin{array}{l}\text { нет } \\
\text { затрудняюсь } \\
\text { ответить }\end{array}$ & 7 & 50 & - & - & 7 & 28 \\
\hline
\end{tabular}




\section{8. Может ли религия внутренне защитить человека, сделать его сильнее?}

Таблича №8.

\begin{tabular}{|l|c|c|c|c|c|c|}
\hline \multicolumn{1}{|c|}{ Ответы } & Девушки - 14 & $\%$ & Юноши - 11 & $\%$ & Количество & Общий \% \\
\hline Да & 3 & 21 & 8 & 73 & 11 & 44 \\
Нет & 8 & 57 & 2 & 18 & 10 & 40 \\
Затрудняюсь & & 21 & 1 & - & 4 & 16 \\
ответить & 3 & 21 & & & \\
\hline
\end{tabular}

\section{9. Как Вы думаете, снижает ли молитва тревогу, беспокойство?}

Таблиияа №9.

\begin{tabular}{|l|c|c|c|c|c|c|}
\hline \multicolumn{1}{|c|}{ Ответы } & Девушки - 14 & $\%$ & Юноши - 11 & $\%$ & Количество & Общий \% \\
\hline Да & 3 & 21 & 8 & 73 & 11 & 44 \\
Нет & 8 & 57 & 2 & 18 & 10 & 40 \\
Затрудняюсь \\
ответить
\end{tabular}

\section{0. Испытываете ли Вы сильные эмоции,} когда читаете молитву?

Таблийа №10.

\begin{tabular}{|l|c|c|c|c|c|c|}
\hline \multicolumn{1}{|c|}{ Ответы } & Девушки - 14 & $\%$ & Юноши - 11 & $\%$ & Количество & Общий \% \\
\hline всегда & - & & - & & - & - \\
часто & 1 & 7 & 9 & 82 & 10 & 40 \\
иногда & 3 & 21 & 1 & 9 & 4 & 16 \\
редко & 10 & 71 & 1 & 9 & 11 & 44 \\
\hline
\end{tabular}

\section{1. Опишите свои эмоциональные чувства «здесь-и-сейчас».}

Таблицุа №11.

\begin{tabular}{|l|c|c|c|c|c|c|}
\hline \multicolumn{1}{|c|}{ Ответы } & Девушки - 14 & $\%$ & Юноши - 11 & \% & Количество & Общий \% \\
\hline позитивные & 2 & 14 & 9 & 82 & 14 & 56 \\
тревожные & 7 & 50 & - & - & 2 & 8 \\
нейтральные & 5 & 36 & 2 & 18 & 9 & 36 \\
\hline
\end{tabular}

\section{2. Чувствуете ли Вы себя защищенным, находясь в храме?}

Таблийа №12.

\begin{tabular}{|l|c|c|c|c|c|c|}
\hline \multicolumn{1}{|c|}{ Ответы } & Девушки - 14 & $\%$ & Юноши - 11 & $\%$ & Количество & Общий \% \\
\hline да & 4 & 28 & 10 & 91 & 10 & 25 \\
нет & 8 & 57 & - & - & 8 & 32 \\
не знаю & 2 & 14 & 1 & 9 & 3 & 12 \\
\hline
\end{tabular}


Анализ анкеты показал, что юноши (прихожане, верующие) более направлены к религиозной вере, чем девушки (неверующие). Респонденты (прихожане) от 73 до 82\% утверждают, что они часто обращаются к религии, она необходима, делает человека лучше, способствует развитию. $82 \%$ прихожан считают, что религия способна внутренне защитить человека, они испытывают положительные эмоции от молитвы, 91\% респондентов чувствуют себя защищенными. Девушки от 29 до 36\% менее религиозны, и, следовательно, 57\% не чувствуют себя защищенными, 50\% испытывают тревожные эмоциональные чувства. Как мы видим, юноши религиозны, эмоционально защищены, девушки эмоционально менее устойчивы, не религиозны, нежели юноши (прихожане), более тревожны, нежели юноши.

По результатам методики Ч.Д. Спилбергера на выявление личностной и реактивной тревожности было выявлено, что у 5 из 11 верующих ситуативная тревожность высокая (45 баллов и более), а у неверующих 7 человек из 14 высокая (45 баллов и более) соответственно $20 \%$ верующие и $28 \%$ неверующие. Тогда как личностная тревожность показала, что у верующих - юноши (11 человек) нет высоких показателей, а у 11 из 14 неверующих - девушки испытуемых высокие показатели тревожности (45 баллов и более), По личностной тревожности у верующие $0 \%$ баллов и у неверующие $44 \%$.

Как нам кажется, религиозная вера представляет собой особое состояние сознания. Находясь в глубоком переживании, а вера и есть переживание, человек погружается в осознание и осмысление своего экзистенциального существования. Религиозность, формирующаяся в периоды социализации, выступает мощным стимулом для выработки положительных эмоций, нахождения себя и направлении своей будущности.

\section{Список литературы}

1. Братусь Б.С. Русская, советская, российская психология. М.: Флинта, 2008. С. 56-188.

2. Василюк Ф.Е. Психология переживания. М.: МГУ, 1984. С. 45-200.

3. Грановская В.А. Психология веры. М.: 2014. С. 189-284. 
4. Петровский А.В. Психология в России. XX век. СПб.: Наука, 2015. С. 146-231.

5. Петровский А.В. Психология и время. СПб.: Наука, 2007. С. 23-37.

6. Фромм Э. Бегство от свободы; Пер. с англ. М.: АСТАльпина, 2017. C. $123-288$.

7. Франкл В. Воля к смыслу; Пер. с англ. М.: Альпина нонфикшн, 2018. C. 23-228.

8. Роджерс К. Клиен-центрированная терапия, учебное пособие. М.: Психотерапия, 2009. С. 476-512.

9. Юнг К.Г. Аналитическая психология и психотерапия. М.: Психотерапия, 2015. С. 23-354.

10. Ялом И. Лечение от любви // Психотерапевтические новеллы. М, 2008. C. 23-288.

11. Смирнов М.Ю. Человек в мире религии и религия в мире человека. https://elibrary.ru/

12. Савченко Е.А., Молчан Э.М. Наука и религия: диалоги о человеке и феноменах его бытия: учебно-методич. пособие. М., 2008. 240 с.

13. Сиверцев Е.Ю. Философия, религия и наука как способы оценки человеком конечности своего существования // Вестник Санктпетербургского университета. Серия 6. Философия. Культурология. Политология. Право. Международные отношения. 2010. №2. С. $13-17$.

14. Фролова И.В. О человеке, обществе и религии // Философия и современность: мысли, понятия, идеи. Уфа: Изд-во Башкирского унта, 2001. С. 114-117.

15. Перфилова В.П. Влияние религии на поведение людей // Современное общество: человек, власть, экономика: Сборник материалов III Международной конференции. Разделы 1-5. 2014. С. 386-390.

\section{References}

1. Bratus' B.S. Russkaya, sovetskaya, rossiyskaya psikhologiya [Russian, Soviet, Russian psychology]. Moscow: Flint, 2008, pp. 56-188.

2. Vasilyuk F.E. Psikhologiya perezhivaniya [Psychology of experience]. Moscow: Moscow State University, 1984, pp. 45-200. 
3. Granovskaya V.A. Psikhologiya very [Psychology of faith]. Moscow: 2014, pp. 189-284.

4. Petrovskiy A.V. Psikhologiya v Rossii. XX vek [Psychology in Russia. Twentieth century]. SPb.: Science, 2015, pp. 146-231.

5. Petrovskiy A.V. Psikhologiya i vremya [Psychology and time]. SPb.: Science, 2007, pp. 23-37.

6. Fromm E. Begstvo ot svobody [Escape from Freedom]; Per. from English M.: ASTALPIN, 2017, pp. 123-288.

7. Frankl V. Volya k smyslu [The will to sense]; Per. from English M.: Alpina nonfixion, 2018, pp. 23-228.

8. Rodzhers K. Klien-tsentrirovannaya terapiya [Klien-centered therapy, study guide]. M.: Psychotherapy, 2009, pp. 476-512.

9. Yung K.G. Analiticheskaya psikhologiya i psikhoterapiya [Analytical psychology and psychotherapy]. M.: Psychotherapy, 2015, pp. 23-354.

10. Yalom I. Lechenie ot lyubvi [Treatment for love]. Psikhoterapevticheskie novelly [Psychotherapeutic novels]. Moscow, 2008, pp. 23-288.

11. Smirnov M.Yu. Chelovek v mire religii i religiya v mire cheloveka [Man in the world and religion in the world of man]. https:/elibrary.ru/

12. Savchenko E.A., Molchan E.M. Nauka i religiya: dialogi o cheloveke $i$ fenomenakh ego bytiya [Science and religion: dialogues about man and the phenomena of his being]. M., 2008. 240 p.

13. Sivertsev E.Yu. Filosofiya, religiya i nauka kak sposoby otsenki chelovekom konechnosti svoego sushchestvovaniya [Philosophy, religion and science as a means of assessing a person's extremity of its existence]. Vestnik Sankt-peterburgskogo universiteta. Seriya 6. Filosofiya. Kul 'turologiya. Politologiya. Pravo. Mezhdunarodnye otnosheniya [Bulletin of St. Petersburg University. Series 6. Philosophy. Culturology. Political science. Right. International relationships]. 2010. №2, pp. 13-17.

14. Frolova I.V. O cheloveke, obshchestve i religii [About man, society and religion]. Filosofiya i sovremennost': mysli, ponyatiya, idei [Philosophy and modernity: thoughts, concepts, ideas]. Ufa: Publishing house of Bashkir University, 2001, pp. 114-117.

15. Perfilova V.P. Vliyanie religii na povedenie lyudey [The influence of religion on people's behavior]. Sovremennoe obshchestvo: chelovek, vlast', 
ekonomika : Sbornik materialov III Mezhdunarodnoy konferentsii [Modern society: people, power, economy: A collection of materials of the III International Conference]. Sections 1-5. 2014, pp. 386-390.

\section{ДАННЫЕ ОБ АВТОРЕ}

Кокоева Разита Тембулатовна, доцент кафедры психологии, кандидат педагогических наук, доцент

Северо-Осетинский государственный университет им. К.Л. Хетагурова

ул. Ватутина, 44-46, г. Владикавказ, 362025, Российская Федерация

nebesa77777@mail.ru

\section{DATA ABOUT THE AUTHOR}

Kokoeva Rosita Embulatovka, Associate Professor of Psychology, Candidate of Pedagogical Sciences, Associate Professor North Ossetian State University Costa 44-46, Vatutina Str., Vladikavkaz, 362025, Russian Federation nebesa77777@mail.ru 